$22^{\text {nd }}$ Discussion Conference of

\section{P.M.M. on Spectroscopy of Partially}

Ordered Macromolecular Systems

21-24 July 2003, Prague, Czech Republic

This conference continues in the tradition of the Prague Meetings on Macromolecules, organized since 1967. It will deal with various aspects of detection and evaluation of order emerging in systems of synthetic as well as natural macromolecules in bulk or solution by molecular spectroscopy. The conference will also tackle relative ordering on various scales accessible to molecular spectroscopy, in particular molecular (preferred conformations, increased persistence length, ordering of low-molecular-weight ligands and counterions), supramolecular (complex formation, short-range ordering interactions) and supermolecular or phase-like (micelles, microphases and other nanostructures, micro- scopic domains in polymer blends, etc.). Main methods probing into emerging order, discussed at the conference, will be high-resolution liquid-and solid-state NMR (spectra, relaxation, spin-diffusion, self-diffusion, etc.) and vibrational spectroscopy (infrared, Raman, micro-Raman imaging, etc.).

\section{Contact Dr. Drahomir Vyprachticky}

Institute of Macromolecular Chemistry, Academy of Sciences of the Czech Republic, Heyrovskeho nam. 2, CZ-162 06 Praha 6, Czech Republic

Tel.: +420 220403251

Fax: +420 235357981

E-mail: sympo@imc.cas.cz

\title{
Calendar of IUPAC Sponsored Conferences
}

\section{Visit www.iupac.org for complete information and further links}

NEW designates a new conference since the last issue

\section{2}

\section{Polymer Science and Technology \\ 2-5 December 2002 \\ IUPAC Polymer Conference on the Mission and Challenges of Polymer Science and Technology, Kyoto, Japan. \\ Prof. Seiichi Nakahama, Faculty of \\ Engineering, Tokyo Institute of \\ Technology, 2-12-1 Ohokayama, \\ Meguro-ku, Tokyo 152-8552, Japan \\ Tel.: +81357342138 \\ Fax.: +81357342887 \\ E-mail: snakahama@aist.go.jp}

\section{3}

\section{Polymer Characterization} 6-10 January 2003

$11^{\text {th }}$ Annual Course on NEW

Polymer Characterization and $11^{\text {th }}$ POLYCHAR World Forum on Polymer Applications and Theory, Denton, Texas, USA.

Dr. Witold Brostow, Department of Materials Science, University of North Texas, Denton, Texas, 76203-5310 USA

Fax: +1 9405654824

E-mail:polychar@marta.phys.unt.edu
Clinical Laboratory

6-7 February 2003

$2^{\text {nd }}$ European Symposium on Clinical Laboratory and In Vitro Diagnostic Industry, Barcelona, Spain Prof. Xavier Fuentes Arderiu, Ciutat Sanitària i Universitària de Bellvitge Servei de Bioquímica Clínica

L'Hospitalet de Llobregat, Catalonia, E-08907 Barcelona, Spain

Tel.: +34932607644

Fax: +34932607564

E-mail:xfa@csub.scs.es

Flow Analysis

17-21 February 2003

The $9^{\text {th }}$ International Conference on Flow Analysis, Geelong, Victoria, Australia.

Dr. Daryl J. Tucker, School of

Biological and Chemical Sciences,

Deakin University, Geelong,

Victoria 3127 Australia.

Tel.: +61352272325

Fax: +61 352271040

E-mail: tucker@deakin.edu.au

\section{Heterocyclic Chemistry}

10-12 March 2003 (Pre-conference 9 March 2003)

$4^{\text {th }}$ Florida Heterocyclic Conference, Gainesville, Florida, USA.

Prof. Alan R. Katritzky, University of
Florida, Dept. of Chemistry, PO Box 117200 Gainesville, FL 32611, USA

Tel.: +1 3523920554

Fax: +1 3523929199

E-mail: katritzky@chem.ufl.edu

Polymer Properties

10-11 April 2003

UNESCO Introductory Course 14-17 April 2003

$6^{\text {th }}$ Annual UNESCO School \& IUPAC Conference on Polymer Properties, Mpumalanga, South Africa.

Prof. R.D. Sanderson, UNESCO Associated Centre for Macromolecules and Materials Institute for Polymers Science, University of Stellenbosch, Private Bag X1, Matieland 7602, South Africa Tel.: +27218083174

Fax: +27218084967

E-mail:rds@sun.ac.za

100 Years of Chromatography 13-18 May 2003

$3^{\text {rd }}$ International Symposium on Separations in BioSciences (SBS '03), follow up to the International Symposia Series "Biomedical Applications of Chromatography and Electrophoresis," Moscow, Russia. Prof. Vadim A. Davankov, 
Nesmeyanov Institute of OrganoElement Compounds, Vavilov str., 28, 119991, Moscow, Russia. Tel.:/Fax: +70951356471 E-mail:davank@ineos.ac.ru

\section{High Temperature Materials}

19-23 May 2003

$11^{\text {th }}$ International Conference on High

Temperature Materials Chemistry

(HTMC XI), Tokyo, Japan.

Prof. Michio Yamawaki, University of Tokyo, Department of Quantum Engineering, 7-3-1 Hongo, Bunkyoku, Tokyo 113-8656, Japan

Tel.: +81358417422

Fax: +81358418633

E-mail:yamawaki@q.t.u-tokyo.ac.jp

Macromolecule Metal Complexes 20-24 May 2003

$\mathrm{X}^{\text {th }}$ International Symposium on Macromolecule Metal Complexes (MMC-X), Moscow, Russia.

Prof. Valerii V. Lunin, Department of Chemistry, Moscow State University, Leninskie Gory, Moscow, 119899, Russia.

Tel.: +70959395377

Fax: +7 0959328846

E-mail:kar@petrol.chem.msu.ru

\section{Ionic Polymerization}

30 June-4 July 2003

International Symposium on Ionic

Polymerization, Boston, MA, USA.

Prof. R. P. Quirk, Department of

Polymer Science, The University of

Akron, Akron, OH 44325-3909, USA.

Tel.: +13309727510

Fax: +1 3309725290

E-mail: quirk@polymer.uakron.edu

Organo-Metallic Chemistry

6-10 July 2003

$12^{\text {th }}$ IUPAC International

Symposium on Organo-Metallic

Chemistry Directed Towards

Organic Synthesis (OMCOS-12),

Toronto, Ontario, Canada.

Prof. Mark Lautens, Department of

Chemistry, University of Toronto,

Toronto, ON M5S 3H6, Canada

Tel: +1 4169786031

E-mail: omcos@chem.utoronto.ca

Spectroscopy of Macromolecular Systems

21-24 July 2003

NEW

$22^{\text {nd }}$ Discussion Conference of P.M.M.on Spectroscopy of
Partially Ordered Macromolecular Systems, Prague, Czech Republic. Dr. Drahomir Vyprachticky,

Institute of Macromolecular

Chemistry, Academy of Sciences of the Czech Republic, Heyrovskeho nam. 2, CZ-162 06 Praha 6, Czech Republic

Tel.: +420220403251

Fax: +420235357981

E-mail: sympo@imc.cas.cz

IUPAC 42nd General Assembly

8-17 August 2003

Ottawa, Ontario, Canada.

IUPAC Secretariat

Tel.: + 19194858700

Fax: +19194858706

E-mail:secretariat@iupac.org

\section{IUPAC 39th Congress}

10-15 August 2003

Chemistry at the Interfaces, Ottawa, Canada.

National Research Council Canada, Montreal Road, Building M-19, Ottawa, ON, Canada K1A OR6

Tel.: +1 6139930414

Fax: +1 6139937250

E-mail: iupac2003@nrc.ca

〈www.iupac2003.org >

See enclosed booklet for

Preliminary Program

Young chemists !! Watch out for

deadline-See page 25

Colloquium

Spectroscopicum NEW

Internationale

7-12 September 2003

$33^{\text {rd }}$ Colloquium Spectroscopicum Internationale 2003, Granada, Spain. Prof. Alfredo Sanz-Medel,

Department of Physical and

Analytical Chemistry, University of Oviedo, C/Julian Claveria, 8 E-

33006 Ovido, Spain

Tel.: + 34985103474

Fax: +34 985103125

E-mail: asm@sauron.quimica.uniovi.es

General and Applied Chemistry

\section{NEW}

21-26 September 2003

XVII Mendeleev Congress on

General and Applied Chemistry,

Kazan, Tatarstan, Russia.

Prof. Alexander I. Konovalov, A.E.
Arbuzov Institute of Organic and

Physical Chemistry, Kazan Scientific

Center of Russian Academy of

Sciences, Arbuzov Str., 8, Kazan

420088, Tatarstan, Russia.

Tel.: +7 (8432) 739365

Fax: +7 (8432) 752253

E-mail: arbuzov@iopc.knc.ru

Medicinal Chemistry

15-18 October 2003

NEW

Polish-Hungarian-German-Italian

Joint Meeting on Medicinal

Chemistry, Krakow, Poland.

Prof. Zdzislaw Chilmonczyk, Drug

Institute, Chemska 30/34, PL-00-

725 Warsaw, Poland

Tel.: +48228515229

E-mail: chilmon@il.waw.pl

\section{How to Apply for IUPAC} Sponsorship

To apply for IUPAC sponsorship, conference organizers should complete an Advance Information Questionnaire (AIQ). The AIQ form is available at <www.iupac.org> or by request to the IUPAC Secretariat, and should be returned between 2 years and 12 months before the conference. Further information on granting sponsorship is included in the AIQ and available online.

\section{Visas}

It is a condition of sponsorship that organizers of meetings under the auspices of IUPAC, in considering the locations of such meetings, should take all possible steps to ensure the freedom of all bona fide chemists from throughout the world to attend irrespective of race, religion, or political philosophy. IUPAC sponsorship implies that entry visas will be granted to all bona fide chemists provided application is made not less than three months in advance. If a visa is not granted one month before the meeting, the IUPAC Secretariat should be notified without delay by the applicant. 


\section{Awards and Honors}

R. Atkinson Receives the ACS Award for Creative Advances in Environmental Science and Technology, 14(3)

C. Bai Awarded SCI's International Medal, 15(1)

A. Bard Awarded ACS's Priestley Medal, 15(1)

E. Carreira Receives the Thieme-IUPAC Prize, 14(3)

D. Knox Receives the Franzosini Award, 16(6)

T. Tidwell Receives CCA's Killam Fellowship, 16(1)

\section{Columns}

Executive Director's Column, 2(3)

Past President's Column, 2(6)

President's Column, 2(1)

Secretary General's Column, 2(2)

Treasurer's Column, 2(5)

Vice President's Column, 2(4)

\section{Conference Announcements}

Advances in Emulsion Polymerization and Latex Technology, 3-7 Jun 2002, 28(1)

Antiprotozoal Chemotherapy, 23-26 June 2002, 24(2)

Bioorganometallic Chemistry, 18-20 July 2002, 24(2)

Capillary Electroseparation Techniques (ITP 2002), 1-4 Sep 2002, 26(3)

CAS/IUPAC Conference on Chemical Identifiers and XML for Chemistry, 1 July 2002, 23(2)

Central European Conference on "Chemistry Towards Biology," 8-12 Sep 2002, 23(2)

Clinical Chemistry, 20-25 Oct 2002, 25(2)

Clinical Laboratory and in vitro Diagnostic Industry, 6-7 Feb 2003, 33(4)

Coordination Chemistry (35-ICCC), 21-26 Jul 2002, 24(3)

Discussion Meeting on Thermodynamics of Alloys, 8-13 Sep 2002, 29(1)

Emulsion, 24-27 Sep 2002, 29(1)

European Conference on Rheology, 1-6 Sep 2002, 29(1)

Flow Analysis, 10-14 Feb 2003, 24(2)

Food Science, 4-6 Sep 2002, 24(2)

Green Solvents for Catalysis, 13-16 Oct 2002, 33(4)

Heterocyclic Chemistry, 10-12 Mar 2003, 34(5)

High-Temperature Materials, 19-23 May 2003, 25(2)

International Symposia on Organosilicon Chemistry, 2530 Aug 2002, 28(1)

Ionic Polymerization, 30 Jun-4 Jul 2003, 34(6)

Luminescence Phenomena, 25-30 Aug 2002, 24(2)

Macromolecule Metal Complexes (MMC-X), 20-24 May 2003, 25(3)

Organo-Metallic Chemistry (OMCOS-12), 6-10 Jul 2003, $34(5)$

Organosilicon Chemistry, 25-30 Aug 2002, 24(2)

Pan-European Younger Chemists' Conference, 30 Sep-2 Oct 2002, 24(3)

Pharmacognosy, 27-31 Jul 2002, 26(3)

Pharmacognosy, 27-31 Jul 2002, 28(1)
Plutonium and Other Actinide Elements, 6-10 July 2003, 25(2)

Plutonium Futures-The Science 2003, 6-10 Jul 2003, 25(3)

Polymer Characterization (POLYCHAR-11), 6-10 Jan 2003, 34(6)

Polymer Properties, 14-17 Apr 2003, 34(6)

Preserving Data, 5-7 Nov 2002, 25(2)

Process Technologies, 18-20 Mar 2002, 28(1)

Purchasing, Servicing and Maintenance of Scientific Equipment, 5-8 Nov 2002, 33(4)

Raw Materials, 26-29 May 2002, 24(2)

Rejuvenating the Learning and Teaching of Chemistry, 30 Nov-4 Dec 2002, 34(5)

Scientific and Technical Data, 29 Sep-3 Oct 2002, 24(2)

Solar Energy and Applied Photochemistry [SOLAR '03], 23-28 Feb 2003, 26(3)

Spectroscopy of Macromolecular Systems, 21-24 July 2003, 35(6)

Stable Isotopes, 7-9 July 2002, 24(2)

World Space Congress 2002, 10-19 Oct 2002, 30(1)

\section{Conference Calendar}

Listing of IUPAC Sponsored Conferences and Symposia, 30(1), 25(2), 26(3), 34(4), 35(5), 35(6)

\section{Feature Articles}

A Preprint Server for Chemistry, 14(4)

Aligning the Revised Red and Blue Books and Preparing for IUPAC Preferred Names, 13(6)

Candid Chemistry, 11(5)

Catalyst: The Museum of the Chemical Industry, 4(1)

Cometh A Digital Dark Age?, 7(6)

Crystallographic Information File (CIF), 4(4)

How Well Are We Using XML in Chemistry?, 7(4)

IOCD: 20 Years of Building Capacity in Chemistry in Developing Countries, 3(3)

Macromolecular Nomenclature and Terminology: A Brief History of IUPAC Activities, 10(6)

Markup Languages-How to Structure Chemistry-Related Documents, 9(4)

Medicinal Chemistry in IUPAC: Accomplishments During the Past Decade and Relationships With Industry, 8(5)

Medicinal Chemistry in the New Millennium, 4(5)

PEDECIBA-Programa de DEsarrollo de CIencias BAsicas, 4(6)

Pesticide Residues: IUPAC Representative's Report on the 34th Codex Committee Session, 14(5)

Preserving Records of Modern Science, 5(1)

Reliable Solubility Data in the Age of Computerized Chemistry: Why, How, and When?, 8(2)

Science and the Public: Learning for the Future, 6(1)

Scientific and Technical Information: IUPAC Representative's Report on the 2002 ICSTI General Assembly, 6(6) 
Small-Scale Chemistry, 8(3)

The Bureau International des Poids et Mesures: Establishing Standards in the Physical Sciences, 4(2)

The Synthesis and Naming of Elements 110 and Beyond, 7(2)

The World Chemistry Congress 2001 and the Young Scientist Awards, 11(3)

Validated Analytical Methods-AOAC's Experience Over 100 Years, 6(3)

XML in Chemistry, 3(4)

\section{Highlights from Pure and Applied Chemistry}

"Heavy Metals"-A Meaningless Term?, 25(5)

Critical Evaluation of Proven Chemical Weapon Destruction Technologies, 21(4)

Critical Evaluation of Stability Constants of Phosphonic Acids, 18(2)

Definitions of Basic Terms Relating to Polymer Liquid Crystals, 24(4)

Definitions Relating to Stereochemically Asymmetric Polymerizations, 23(6)

Future Requirements in the Characterization of Continuous Fiber Reinforced Polymeric Composites, 22(5)

Generic Source-Based Nomenclature for Polymers, 16(2)

Guidelines for the Representation of Pulse Sequences for Solution-State Nuclear Magnetic Resonance Spectrometry, 17(3)

Harmonized Guidelines for Single-Laboratory Validation of Methods of Analysis , 26(5)

Information Essential for Characterizing a Flow-Based Analytical System, 21(5)

JCAMP-DX. A Standard Format for the Exchange of Ion Spectrometry Data, 18(3)

Modeling Lifetime and Degradability of Organic Compounds in Air, Soil, and Water Systems, 20(1)

Molality-Based Primary Standards of Electrolytic Conductivity, 18(3)

Molecular Basis of Biodiversity, Conservation, and Sustained Innovative Utilization, 23(5)

Naming of New Elements, 24(5)

NMR Nomenclature. Nuclear Spin Properties and Conventions for Chemical Shifts, 18(3)

Nomenclature for the $\mathrm{C}_{60^{-}} \mathrm{I}_{\mathrm{h}}$ and $\mathrm{C}_{70^{-}} \mathrm{D}_{5 \mathrm{~h}(6)}$ Fullerenes, 22(5)

Phane Nomenclature, 25(5)

Polyaniline. Preparation of a Conducting Polymer, 26(5)

Potentiometric Selectivity Coefficients of Ion-Selective Electrodes, 24(6)

Quantum Chemical B3LYP/cc-pvqz Computation of Ground-State Structures and Properties of Small Molecules with Atoms of $Z<18$ (Hydrogen to Argon), 17(2)

Selectivity in Analytical Chemistry, 21(1)

Standards in Isothermal Microcalorimetry, 17(2)

Studies on Biodegradable Poly[hexano-6-lactone] Fibers, 26(5)

Sulfate-Sensing Electrodes. The Lead-Amalgam/LeadSulfate Electrode, 21(5)

Use of Legendre Transforms in Chemical Thermodynamics, 20(1)

\section{IUPAC Forum}

Breaking Away from the Old Three Ss, 11(2)

IUPAC Divisions and Education: A Case for Joint Projects, 10(1)

On the Reality of Virtual Libraries, 16(4)

Young Chemists Travel Far with Canadian National Committee Awards, 12(2)

Young Observers Programs: Getting New Expertise Involved in IUPAC, 7(1)

\section{IUPAC News}

2002 Winners of the IUPAC Prize for Young Chemists, 19(4)

Chemical Education International, 18(5)

Chemical Nomenclature and Structure Representation, 12(2)

IUPAC-Empfehlungen, 19(5)

New Paid Affiliate Members Mean More Sponsored Affiliates in Developing Countries, 13(1)

Nomenclature of Inorganic Chemistry, 14(2)

Relocating to Cyberspace, 12(3)

The "Orange Book" Online, 19(5)

The Address is www.iupac.org, 16(6)

The Analytical Chemistry Division, 16(4)

Whither Green Chemistry? A Look at CHEMRAWN XIV, 13(1)

Young Chemists to the $39^{\text {th }}$ IUPAC Congress, Ottawa, August 2003, 18(5)

\section{IUPAC Projects}

Chemical Actinometry, 20(5)

Concepts and Structure for Requests in Clinical Laboratories, 21(6)

Conducting Polymer Colloids and Nanofilms, 20(5)

Educating Chemists and the Public About Risk Assessment, 18(1)

Evaluated Kinetic Data for Atmospheric Chemistry, 17(1)

Global Use of the C-NPU Concept System for Properties in Toxicology, 22(6)

Glossary for Toxicokinetics of Chemicals, 15(3)

Impact of Scientific Developments on the Chemical Weapons Convention, 19(1)

Information for Task Group Chairmen, 20(5)

New SIT Software Makes Speciation Calculations Easier, 18(6)

New Solubility Data Projects, 20(6)

Nomenclature for Rotaxanes, Catenanes, and Macromolecular Rotaxanes, 16(3)

Performance Evaluation Criteria for Preparation and Measurement of Macro- and Microfabricated IonSelective Electrodes, 19(6)

Pest Management for Small-Acreage Crops: A Cooperative Global Approach, 20(4)

Properties and Units for Transfusion Medicine and Immunohaematology, 21(6)

Recommendation on the Use of Countercurrent Chromotography in Analytical Chemistry, 15(3)

Recommendations for NMR Measurements of High pK Values and Equilibrium Constants in Strongly Basic Solutions, 19(6) 
SCOPE/IUPAC International Symposium on Endocrine Active Substances, 16(2)

Standard Potentials of Radicals, 15(3)

\section{New Books and Publications}

Actinide Carbon Compounds, 23(1)

Advanced Organic Chemistry-Part A: Structure and Mechanism, Part B: Reactions and Synthesis, 28(5)

$\mathrm{C}_{2+}$ Nitroalkanes With Water or Organic Solvents: Binary and Multicomponent Systems, 28(5)

Characterization of Compounds in Solution: Theory and Practice, 20(2)

CRC Handbook of Optical Resolutions via Diastereomeric Salt Formations, 21(2)

Electrochemistry and Interfacial Chemistry for the Environment, 19(3)

Free-Radical Polymerization: Kinetics and Mechanism, 27(5)

Green Chemistry in Africa, 27(6)

Green Chemistry-the Japanese translation of the special topic issue of Pure and Applied Chemistry (Vol. 72, No. 7, 2000), 20(3)

Handbook of Pharmaceutical Salts: Properties, Selection, and Use, 20(3)

Handbuch für die Systematische Nomenklatur der Organischen Chemie, 28(4)

Heat Capacity of Liquids: Critical Review and Recommended Values, 21(3)

Interactions Between Soil Particles and Microorganisms: Impact on the Terrestrial Ecosystem, 26(4)

Ionic Poylmerization (IP'01), 27(6)

IUPAC Handbook 2002-2003, 27(4)

Metal and Ammonium Formate Systems, 22(1)

Modern Coordination Chemistry-The Legacy of Joseph Chatt, 29(5)

Mycotoxins and Phycotoxins in Perspective at the Turn of the Millennium, 23(1)

New Books from the American Oil Chemists' Society Press, 21(2)

New Books from the World Health Organization, 21(2)

Nomenclature of Organic Compounds, Principles and Practice, 23(1)

Non-Conventional Polymer Dispersions, 26(4)

Non-Metals in Liquid Alkali Metals, 21(3)

Pesticide Formulation and Application Systems: A New Century for Agricultural Formulations, 22(3)

Polymer Characterization and Materials Science, 21(3)

Polymer Networks, 22(1)

Polymerization Processes and Polymer Materials, 20(2)

Polymers in Medicine, 22(1)

Solubility of Ethyne in Liquids, 27(4)

The Biogeochemistry of Iron in Seawater, 20(2)

The Science of Sweeteners, 26(6)

Vermeer's Camera, 28(6)

\section{Provisional Recommendations}

Definitions of Terms Related to Polymer Blends, Composites and Multiphase Polymeric Materials, 24(6)

Quantities, Terminology, and Symbols in Photothermal and Related Spectroscopies, 19(2)
The Naming of New Elements, 19(2)

Thermochemistry of Chemical Reactions: Terminology, Symbols, and Experimental Methods for the Determination of Bond Energies, 16(3)

\section{Reports from Conferences}

Advanced Materials, IUPAC WAM II, 13-16 Feb 2002, Bangalore, India, 22(3)

Analytical Sciences, ICAS2001, 6-10 Augt 2001, Tokyo, Japan, 22(2)

Biodiversity, ICOB-3, 3-8 Nov 2001, Antalya, Turkey, 30(5)

Bioinformatics 2002: North-South Networking, 6-8 Feb 2002, Bangkok, Thailand, 28(6)

Chemistry and Quality of Life, 8 ICCA, 30 Jul-4 Aug 2001, Dakar, Sénégal, 29(4)

CHEMRAWN XIV Follows Up With Green Chemistry Activities, 27-28 May 2002, Bangkok, Thailand, 29(6)

Functional p-Electron Systems, 30 May-4 Jun 2002, Ulm, Germany, 30(6)

Heterocyclic Chemistry, 6-8 Mar 2002, Gainesville, Florida, USA, 31(4)

Ionic Polymerization, 22-26 Oct 2001, Crete, Greece, 30(4)

Macromolecules and Materials Science, 23-28 Mar 2002, Stellenbosch, South Africa, 31(5)

Macromolecules-Metal Complexes, MMC-9, 19-23 Aug 2001, Brooklyn, New York, USA, 29(4)

Medicinal Chemistry, 2-6 Sep 2001, Budapest, Hungary, 22(2)

Nuclear Analytical Techniques in the Life Sciences, NAMLS-7, 16-21 Jun 2002, Antalya, Turkey, 32(5)

Organic Synthesis, ICOS-14, 14-19 Jul 2002, Christchurch, New Zealand, 31(6)

Organometallic Chemistry Directed Towards Organic Synthesis, OMCOS-11, 22-26 Jul 2001, Tapei, Taiwan, 24(3)

Physical Organic Chemistry, ICPOC-16, 4-9 Aug 2002, San Diego, California, USA, 32(6)

Plasma Chemistry, ISPC-15, 9-13 Jul 2001, Orléans, France, 24(1)

Polymer Characterization, POLYCHAR-10, 7-11 Jan 2002, Denton, Texas, USA, 30(4)

Prohibiting Chemical Weapons, 30 Jun-3 Jul 2002, Bergen, Norway, 33(5)

Safety in Chemical Production, 30 Jul-4 Aug 2001, Dakar, Sénégal, 25(1)

Solubility Phenomena-Application for Environmental Improvement, 10 ${ }^{\text {th }}$ ISSP, 21-26 Jul 2002, Varna, Bulgaria, 31(6)

Solution Chemistry, 27 $7^{\text {th }}$ ICSC, 26-31 Aug 2001, Vaals, Netherlands, 23(3)

\section{Web Reviews}

Co-Operation on International Traceability in Anaytical Chemistry

(CITAC), 32(4)

Spare Parts oon the Web, 27(1)

The International Network for the Availability of Scientific Publications (INASP), 32(4)

Valid Analytical Measurement, 27(1)

Visualized Thermodynamics, 32(4) 